\title{
Interactive comment on "SCARLET-1.0: SpheriCal Approximation for viRtuaL aggrEgaTes" by Eduardo Rossi and Costanza Bonadonna
}

\section{Eduardo Rossi and Costanza Bonadonna}

eduardo.rossi@unige.ch

Received and published: 10 April 2021

We really thank the reviewer for his help in revising and improving the manuscript. We really appreciated his contribute. Here we attach a zip file with two separate pdfs in it: - The first one with our replies to the major comments. - The second one with his previous pdf, commented.

Please also note the supplement to this comment:

https://gmd.copernicus.org/preprints/gmd-2020-346/gmd-2020-346-AC1-

supplement.zip

Interactive comment on Geosci. Model Dev. Discuss., https://doi.org/10.5194/gmd-2020-346, 
2020.

GMDD

Interactive

comment 